\title{
Nephropathy due to Cisplatin
}

National Cancer Institute

\section{Source}

National Cancer Institute. Nephropathy due to Cisplatin. NCI Thesaurus. Code C123136.

Kidney damage resulting from cisplatin. 